\title{
Remote Sensing Monitoring and Ecological Risk Assessment of Landscape Patterning in the Agro-Pastoral Ecotone of Northeast China
}

\author{
Min Guo $\mathbb{D}^{1}$ and Shijun Wang $\mathbb{D}^{2}$ \\ ${ }^{1}$ School of Earth Sciences, Jilin University, Changchun 130061, China \\ ${ }^{2}$ School of Geographical Sciences, Northeast Normal University, Changchun 130024, China \\ Correspondence should be addressed to Shijun Wang; wangsj@nenu.edu.cn
}

Received 27 August 2020; Revised 19 November 2020; Accepted 26 February 2021; Published 10 March 2021

Academic Editor: Ning Cai

Copyright (C) 2021 Min Guo and Shijun Wang. This is an open access article distributed under the Creative Commons Attribution License, which permits unrestricted use, distribution, and reproduction in any medium, provided the original work is properly cited.

\begin{abstract}
The agro-pastoral ecotone, an ecological transition zone connecting adjacent areas of agricultural planting area and grassland animal husbandry, has three features: a complex natural condition, relatively pronounced population pressure, and a fragile ecological environment. In this study, we conducted an ecosystem risk assessment in the western part of Jilin Province, China, based on multiscale and multitemporal remote sensing images and land-use data. Furthermore, we focused on land-use change from 1995 to 2015 by applying the dynamic change information survey method and carrying out a transfer track analysis. The results revealed three main findings. (1) The ecological risk index at the scale of $3 \mathrm{~km} \times 3 \mathrm{~km}$ harbors significant spatial correlation. (2) The ecological risk index of unutilized land, forest land, and grassland is relatively high for each, and their anti-interference ability is weak, while the ecological risk index of construction land and water area is the lowest. (3) Human interference, e.g., construction activities and cultivated land occupation, is the leading factor driving the exacerbation of ecological risk and frequent land-use type conversions. At the study period's end, a trend of slight contraction in the high-risk areas was found, indicating that land-use regulation and land protection policies have had significantly positive impact upon the lands' ecological value. The overall study identified a reasonable research scale for eco-environmental risk assessment and discerned relationships between regional land-use changes through geospatial analysis. Moreover, our findings can help provide practical case study information applicable to similar regions with agro-pastoral ecotones.
\end{abstract}

\section{Introduction}

Over the past 20 years, China's rapid urbanization has caused many complex social and economic problems, such as a population explosion, the expansion of built-up areas, and ecological issues [1-3]. Interference from human activities places more pressure on natural habitats, directly affecting the structure and function of natural ecosystems, which also causes complex ecological security problems, such as environmental pollution, land degradation, and biodiversity decline.

Land-use and land cover change (LUCC) play an important role in the research domain of land-use science and sustainable development. Quantitative measurements of land-use landscape patterning and land-use change are of paramount significance for better understanding both regional land evolution and ecological security. Moreover, unreasonable human activities cause serious damage to considerable portions of ecological land because of the latter's limited carrying capacity. Unreasonable land-use activities foster a greater degree of ecological risk to the landscape, which inevitably influences the regional scales of land-use patterns [4]. Landscape ecological risk assessment can provide potential insight on how to ameliorate the unreasonable use of land resources, by coupling the perspectives of geography and ecology. Generally, this type of assessment takes a regional landscape as the study object to quantitatively evaluate the complex ecological effects generated by land-use change. 
Ecological risk assessment, a field of research that has swiftly expanded and developed within the last decade, is the process of assessing the adverse consequences for the ecosystem when its components are under stress from external factors. The standard methods and models used in regional ecological risk assessment include the relative risk model, the causal analysis method, and the PETAR model. The relative risk model pays more attention to the interaction between multiple sources of risk, various stress factors, and multiple ecosystems [5]. Causality analysis is a large-scale risk assessment method based on the causal relationships between stress factors and their possible impacts [6]. The PETAR model is mainly divided into three parts [7]: (1) primary evaluation, which mainly determines the joint impact of risk sources and pressure factors; (2) regional evaluation, which classifies the risk sources and pressure factors in a given region of study; and (3) local evaluation, which derives the mathematical relationships between risk sources, pressure factors, and evaluation endpoints. With ongoing advances in computer technology, both geographic information systems and remote sensing techniques are becoming more widely used in regional ecological risk assessments.

The agro-pastoral ecotone is a type of ecological transition zone, one that links an agricultural planting area to a grassland animal husbandry area and is distinguished by its special geographical location. Against the background of global climate and social activity changes, the ecological environment is becoming more sensitive and fragile. Located in the transition zone of "semihumid agricultural area" and "semiarid pastoral area," the region of Western Jilin Province belongs to the typical agro-pastoral ecotone found in Northeast China, where the climate is arid and the soil is loose. This region is among those with the high environmental sensitivity in Northeast China. In recent years, due to interference from natural factors and human activities, grasslands in this region have been degraded over an extensive area and land salinization has also intensified. The basic structure and function of the grassland ecosystem have been degraded or lost entirely, with its general stability weakened. Therefore, it is imperative that we re-examine the environmental and development issues in this region from the perspective of a human-land harmonious development and land ecological security management.

The significance of ecological risk assessment is well known and has already been widely discussed in the literature. Yet, the value of ecological risk assessment for optimizing land-use pattern and allocation is often ignored, with little research done on multiscale ecological risk assessments. An in-depth understanding of the relationship between land-use and ecological risk will not only help to better plan land-use patterns but also provides a rational basis for policymaking. Also, further analysis of the relationship between land-use change and internal transition between different land-use patterns can reveal the likely driving factors of ecological risk. Given the overall exacerbation of ecological risk in China, certain land policies-such as "land consolidation," "returning farmland to forest," and "grassland projects" - are being implemented by government to mitigate it. With demand mounting for ecological environment protection in China, it is crucial to scientifically measure and analyze the driving factors of ecological risk, as these are needed to formulate proper landuse planning and policy. Such knowledge can be used to optimize land-use patterns and maximize the land-use values by scientifically assigning land-use types after understanding the ecological land risk they face and the landuse changes they undergo.

Taking the region of western Jilin Province as a case example, this paper proposes an ecological risk assessment model based on multiscale and multitemporal remote sensing imagery. The dynamic changes and transition relationships of different land-use categories were studied by using a comprehensive measurement method. This study had three objectives. (1) To describe the temporal and spatial changes of ecological risk in western Jilin Province during the past 20 years, so as to reveal the process of its landscape evolution; (2) to quantitatively analyze land-use change and track it in space and time, by applying two methods: landuse dynamic degree measurement and land-use trajectory analysis; and (3) to comprehensively explore the possible driving factors of ecological risk. Generally, the aim of this study is to provide a scientific evaluation model useful for landscape ecological risk assessment and then analyze the relationships between regional land-use changes, thereby providing a practical case study applicable to typical similar areas elsewhere.

\section{Materials and Methods}

2.1. Summary of the Study Region. The western part of Jilin Province is located in the southwest of the Songnen Plain, and it includes the eastern part of the Horqin prairie and the southern part of the Songnen grassland. The northern and western parts of Jilin Province, respectively, border Heilongjiang Province and the Inner Mongolia autonomous region, containing Baicheng City and Songyuan City. Geographically, the study region is located at $121^{\circ} 38^{\prime}$ to $126^{\circ}$ $12^{\prime} \mathrm{E}$ and $43^{\circ} 58^{\prime}$ to $46^{\circ} 19^{\prime} \mathrm{N}$ (Figure 1 ), covering a vast space, whose land area is $46900 \mathrm{~km}^{2}$. Its terrain to the east, south, and west lies at higher elevation while that to the north and middle is low lying; its overall shape is like a dipper with a total 6.46 million population. Here, the continental monsoon climate of the North Temperate Zone prevails, with an annual average temperature of $4-6^{\circ} \mathrm{C}$ and a yearly solar radiation total of $5000-5400 \mathrm{MJ} / \mathrm{m}^{2}$. Over the last 50 years, the average yearly precipitation in the western part of Jilin Province has tended to decrease while its average annual evaporation has shown a trend of increase [8-10].

2.2. Data Sources. The remotely sensed data came from the land-use/land cover remote sensing monitoring database in China. The Landsat TM/ETM and Landsat8 remote sensing imagery data for the study area in the years 1995, 2005, and 2015 were used as the information source; the bands of these remote sensing images were synthesized and corrected in Envi v4.5 software (Exelis Visual Information Solutions Inc.). By combining the topographic map of the study region 


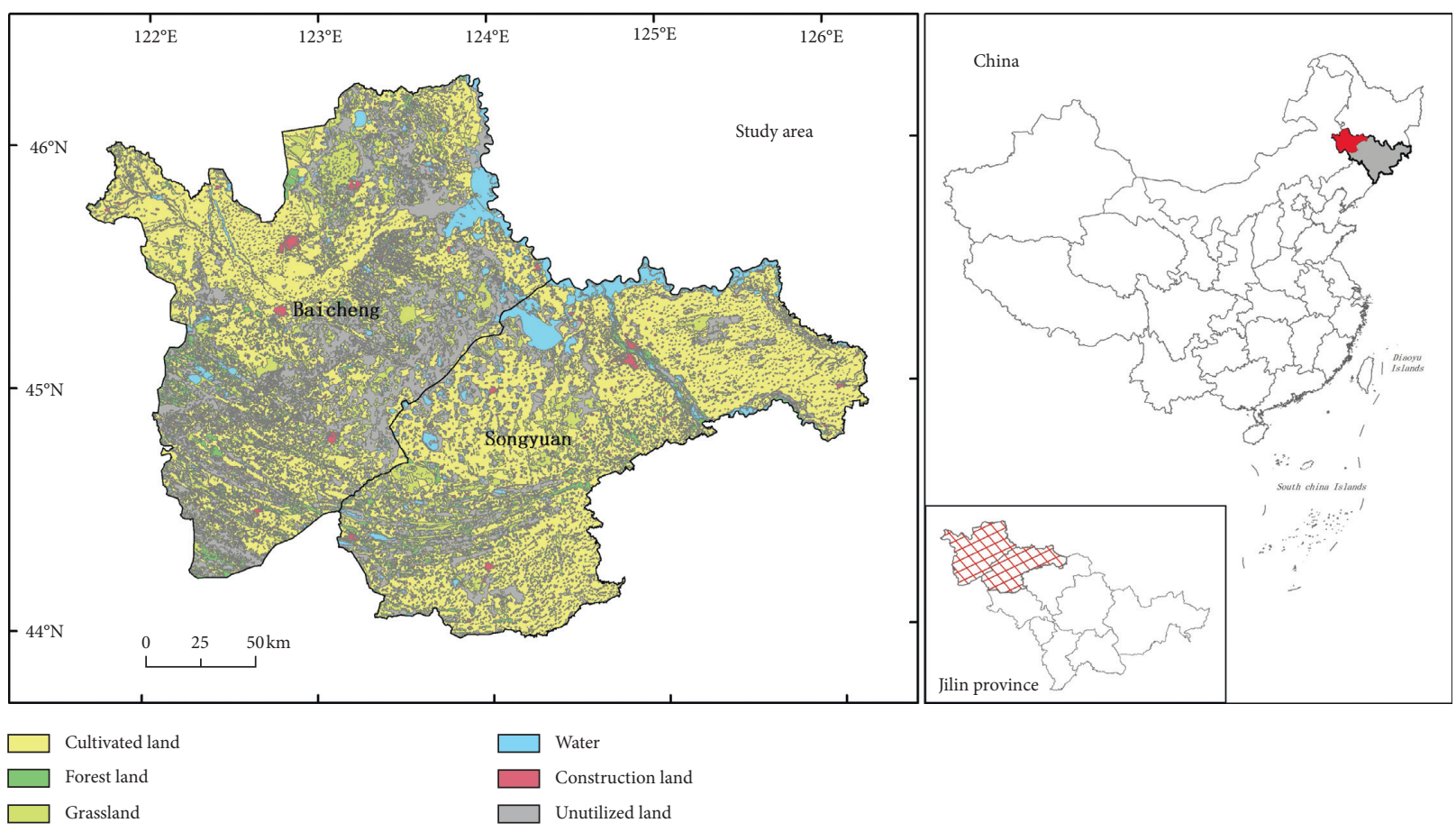

FIgURE 1: Location and land-use map of the study region (Western Jilin Province) in China. On the left, the area of studied cities was shown. On the right, Jilin province is marked in red and grey in China map while the two studied cities were marked as red in China map and Jilin province map.

with land-use map data of its two main cities, the vector files of six land-use categories, namely, cultivated land, forest land, grassland, water, construction land, and unutilized land, were obtained in ArcGIS v10.5 software (ESRI Inc.). Their vector data were converted to a unified projection and coordinate system in ArcGIS 10.5. Meanwhile, the study region was divided into 10 evaluation units-that is, by administrative boundary and into different countries-to indicate land-use changes at the county level and ensure feasibility when cooperating with other planning departments on decision-making. Besides, the previous landscape ecology study suggests that, to comprehensively reflect the landscape pattern information around the sampling sites, the area of landscape samples should be $2-5$ times the average area of landscape patches [11]. Here, we set the grid cell size to three spatial scales: $5 \mathrm{~km} \times 5 \mathrm{~km}, 3 \mathrm{~km} \times 3 \mathrm{~km}$, and $1.5 \mathrm{~km} \times 1.5 \mathrm{~km}$ to improve the calculation intensity and accuracy. Social and economic statistical data were derived from the Jilin Statistical Yearbook (https://www.cnki.net) and relevant statistical bulletins ("http://www.jlbc.gov.cn" and "http://www.jlsy.gov.cn").

2.3. Ecological Risk Index Model. The regional ecological risk reflects the ability of a regional ecosystem to resist external interference and its internal self-regulation and recovery. Different land-use types harbor distinct resiliency to external factors' interference. Correspondingly, they may also differ in how the natural succession of their ecological landscape structure is promoted, as well as adjustments to their overall function and structure and biodiversity maintenance
$[12,13]$. According to the landscape structure of the regional ecosystem, this study selected the landscape interference index $\left(E_{i}\right)$ and landscape fragility index $\left(F_{i}\right)$ through which a comprehensive land-use ecological risk index model is built. Given the landscape structure, this quantitative ecological risk index (ERI) was then used to analyze the ecological risk and its change in Western Jilin Province.

2.3.1. Landscape Interference Index $\left(E_{i}\right)$. This index gauges the degree of perturbations to each landscape structure by human activities or natural changes. The landscape fragmentation index $\left(C_{i}\right)$, reciprocal of fractal dimension $\left(M_{i}\right)$, and landscape dominance index $\left(D_{i}\right)$ are selected to determine the landscape interference degree $\left(E_{i}\right)$, using this formula [14]:

$$
E_{i}=a \times C_{i}+b \times M_{i}+c \times D_{i},
$$

where $C_{i}$ is the index of fragmentation, for which a smaller value indicates a lower degree of habitat fragmentation; $M_{i}$ is the reciprocal of the fractal dimension (MFPD), which if closer to 1 , simpler the geometry is, and the more disturbed is the land, whereas if closer to 2, the structuring is more complex and more natural; and $D_{i}$ is the dominance index, indicating the degree of control by the landscape type. Therefore, the interference index constructed by these three indicators can better convey the degree of landscape interference. In the above equation, $a, b$, and $c$ are the weights of the corresponding landscape index. Based on the actual situation of the study area and pertinent research findings of other study [11], the weight value of the fragmentation index 
was set highest (weight $=0.5$ ), followed by that for the reciprocal of fractal dimension index (weight $=0.3$ ) and the dominance index (weight $=0.2$ ). follows:

The landscape fragmentation index $\left(C_{i}\right)$ formula is as

$$
C_{i}=\frac{n_{i}}{A_{i}},
$$

where $n_{i}$ is the number of patches on the landscape and $A_{i}$ is the total area of the landscape.

The formula for the landscape fractal dimension $\left(M_{i}\right)$ is as follows:

$$
\begin{aligned}
M_{i} & =\frac{1}{\mathrm{MPFD}}, \\
\mathrm{MPFD} & =\sum_{i=1}^{m} \sum_{j=1}^{n} \frac{2 \ln \left(0.25 P_{i j}\right)}{\ln \left(a_{i j}\right)},
\end{aligned}
$$

where $P_{i j}$ is the perimeter of a given patch and $a_{i j}$ is the patches' area.

The formula for the landscape dominance index $\left(D_{i}\right)$ is as follows:

$$
\begin{aligned}
D_{i} & =H_{\max }+\sum_{i=1}^{m} P_{k} \ln \left(P_{k}\right) \\
H_{\max } & =\ln (N)
\end{aligned}
$$

where $H_{\max }$ is the maximum of the diversity index, $P_{k}$ is the probability of patch type $k$ appearing in landscape, and $N$ is the total number of patches.

2.3.2. Landscape Fragility Index $\left(F_{i}\right)$. We assigned relative weights to six landscape categories according to expert scoring, by referring to the research findings reported by others, to reflect the fragility of each landscape type [15]. The unutilized land received a score of 7 , and likewise forest land a 5, grassland a 5 , cultivated land a 3 , construction land a 1 , and water a 1 . On this basis, the score results were normalized to build the fragility index of each landscape type in the study region.

2.3.3. Landscape Loss $\left(R_{i}\right)$. The landscape loss index, which is the combination of $E_{i}$ and $F_{i}$ in a given sample area, represents the extent of natural loss when the landscape type is disturbed. It effectively combines landscape type with land-use fragility information. The formula for it is as follows:

$$
R_{i}=E_{i} \times F_{i} .
$$

Then, the ecological risk index (ERI) is calculated this way:

$$
\mathrm{ERI}_{i}=\sum_{i}^{N} \frac{A_{k i}}{A_{k}} R_{i}
$$

where $N$ is the total number of patches; $A_{k i}$ is the patches' area; $A_{k}$ is the area of the risk unit; and $R_{i}$ is the loss index of each unit.

2.4. Land-Use Change Rate and Change Intensity. The rate of land-use change and its intensity can be used to effectively measure the relative area change of a certain land-use type [16]. The formula for the change rate is

$$
C=\frac{U_{b}-U_{a}}{U_{a}} \times 100 \%
$$

where $C$ is the change rate of a given land-use category during the study period and $U_{a}$ and $U_{b}$ are the land areas of the initial year and final year, respectively. The formula for change intensity is as follows:

$$
K=\frac{1}{T} \times \frac{U_{b}-U_{a}}{U_{a}} \times 100 \%,
$$

where $K$ is the change intensity of a given land-use category during the study period; $U_{a}$ and $U_{b}$ are the land areas of the initial year and final year, respectively; and $T$ is the length of the study period.

2.5. Land-Use Change Trajectories Analysis. Trajectories analysis is a method of portraying the dynamic land-use changes over time. To do this, the parcel states of each node are recorded during a time series and inserted into a new trajectory map, through a raster overlaying analysis $[17,18]$. The spatial statistical analysis of the trajectory map could then be used to distinguish the spatial and temporal transfer characteristics of land use in the study period. The changed land-use track in the time series can be represented by a change code, whose number represents the land-use type in different periods. In this way, the track code can denote the track of land-use type change at each time point assessed (Figure 2). According to the land-use classification system of the study region, the land-use types coded are as follows: "1" stands for "cultivated land," and likewise, "2" for "forest land," "3" for "grassland," "4" for "surface water," "5" for "construction land," and "6" for "unutilized land."

\section{Results}

3.1. Multiscale Ecological Risk Assessment and Analysis. The ecological risk index (ERI) values at different scales for each risk unit in Western Jilin Province were calculated in ArcGIS according to the above-defined calculation formulae. For the three spatial scales, the study area was divided into 21504, 5517, and 2048 risk units, respectively, by $1.5 \mathrm{~km} \times 1.5 \mathrm{~km}, 3 \mathrm{~km} \times 3 \mathrm{~km}$, and $5 \mathrm{~km} \times 5 \mathrm{~km}$ grids, which were used for the sampling and analyses (Figure 3).

As seen in the figure, the ecological risk index of the study region displayed certain regularity when examined at multiple spatial scales. Simply put, the minimum recognizable patch area increased with an increase in the scale of inquiry, so the corresponding ecological risk index decreased after a certain amount of aggregation. To further 


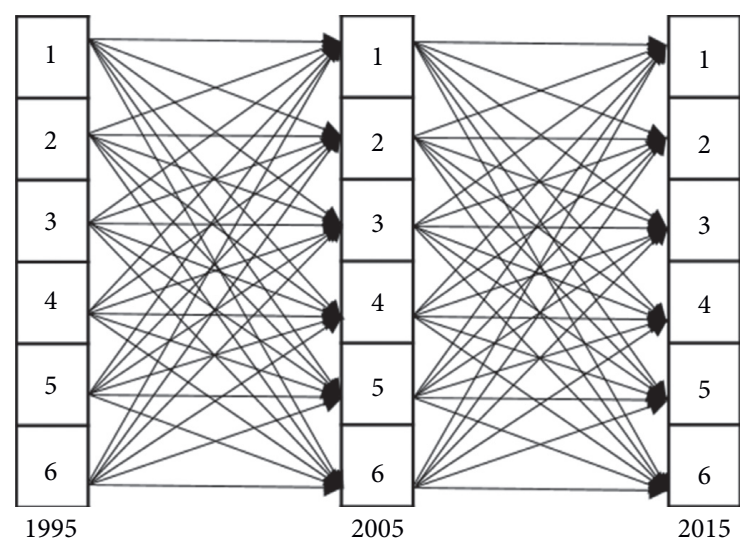

Figure 2: Diagram of all the possible trajectories of land-use change.

determine the appropriate scale, the spatial autocorrelation analysis of the study region's ecological risk units at each scale was carried out by calculating Moran's I index (Table 1). According to the global autocorrelation analysis, Moran's I of the $3-\mathrm{km} \times 3-\mathrm{km}$ grid scale was generally the highest, all significant at $P<0.01$, being $0.7752,0.7339$, and 0.7354; hence, its spatial autocorrelation was the strongest. Therefore, the risk unit on a scale of $3 \mathrm{~km} \times 3 \mathrm{~km}$ was used here on.

3.2. Spatial Evolution of Ecological Risk. The number and area of patches of each land-use type were extracted with the patch analyst extension module of ArcGIS, and the risk index is then calculated to generate the ecological risk index table of each land-use type in Western Jilin Province (Table 2). The ecological risk index of unutilized land, forest land, and grassland was each $>1$, suggesting that these ecosystems in early stages of succession have weak antiinterference ability, low biodiversity, a simple food chain structure, and increased risk to its ecological environment. The ecological index of cultivated land was ranked second, having a strong ability to resist external interference. However, the ecological risk index of construction land and water area was both lower, indicating their respective ecological environments harbored strong resistance to risk.

To analyze the spatial distribution of ecological risk, the risk index can be classified by a grading method as "lower risk area" $(\mathrm{ERI}<0.2)$, "low-risk area" $(0.2 \leq \mathrm{ERI}<0.4)$, "medium-risk area" $(0.4 \leq \mathrm{ERI}<0.6)$, "high-risk area" $(0.6 \leq \mathrm{ERI}<0.8)$, or "higher risk area" $(0.8 \leq \mathrm{ERI})$ [19]. According to the statistics of different ecological risk areas (Figure 4), evidently, the lower ecological risk, low ecological risk, and high ecological risk areas in western Jilin Province increased significantly from 1995 to 2005, of which the last increased the most, by 2.9 times. This was mainly due to the interference of climate change and human activities in Western Jilin Province in the past 10 years. The landscape of saline-alkali land had expanded, perhaps thereby increasing the fragmentation and vulnerability of land. The increase in low ecological risk area was mainly due to the increase in cultivated land and low landscape fragmentation that occurred from 1995 to 2005. From 2000 to 2015, the coverage of the low and lower ecological risk areas both increased slightly, mainly due to greater landscape fragmentation in the agricultural areas under the long-term development and utilization of humans, from 2000 to 2015. Concurrently, high and medium ecological risk areas decreased slightly in coverage, largely due to the people's raised awareness of ecological environment protection since 2000 but also in part because salinization in western Jilin Province has been somewhat controlled.

Examining their spatial distributions revealed that the low ecological risk areas in 1995 were mainly located in the northeast and northwest of the study region, and these belong to the agricultural areas in the west of Jilin Province (Figure 5). The terrain of these areas is relatively high. Around this region, the soil is rich, consisting principally of black soil and chernozem. Moreover, since the climate is suitable for plants, vegetation grows luxuriantly here, and the landscape features mainly crop-cultivated lands, in addition to swamp, and grassland ecosystems. Overall, these areas have excellent ecological environment with little landscape fragmentation, and thus their landscape ecological risk is low due to the low landscape vulnerability.

The middle ecological risk areas are mainly concentrated in the west of Changling, Eastern Taonan, Zhenlai, Da'an, and Tongyu. The soil in these parts is mainly meadow soil, and the land categories found there are mainly cultivated land and grassland, which confer no significant improvement to the ecological environment. The high ecological risk areas are mostly located in the middle and southwest of the study region, being mainly found in Tongyu, southern Da'an, and the east of Zhenlai. Their terrain is low in elevation, whose soil is mostly aeolian sandy soil and barren. Under the arid climate conditions there, land salinization and desertification are more likely to happen. The landscape there features mainly saline-alkali land and grassland. The status of the ecological environment is dismal, the land is fragile, and the landscape ecological risk level is high.

By 2000, such high-risk landscape ecological risk areas in western Jilin Province showed a conspicuous trend of expansion, now mainly concentrated in the southwest and central part of the study region, including Tongyu, Zhenlai, Da'an, and the west of Changling. The main reason for this phenomenon is the severe land salinization in these parts and their poor climatic conditions. From 1995 to 2000, the landscape area of saline-alkali land increased significantly, and the ecological risk index was high. Compared with 1995, the low ecological risk areas were still concentrated in the northeast and northwest of the study region. The dynamic changes of land in these parts are less pronounced, and most of them occurred for cultivated land, so the net change in landscape ecological risk index is not apparent. By 2015, the high ecological risk areas in Western Jilin Province were remained clustered in the central and southwest of the study region, though their coverage shrunk slightly when compared with that in 2000 .

In tandem, to more clearly reveal the local spatial distribution characteristics of ecological risk units, we conducted a hotspot analysis-using the Getis-Ord GI* 

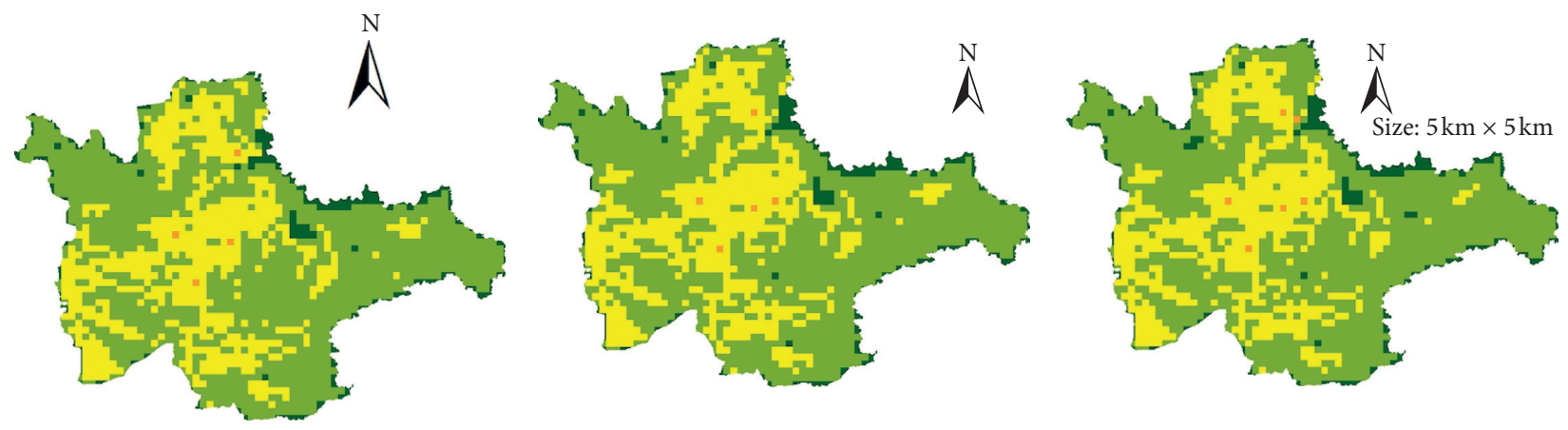

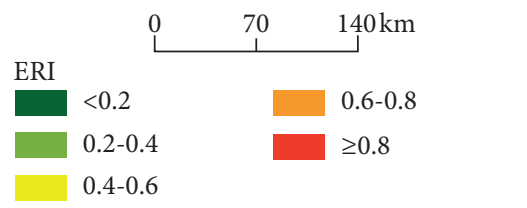

(a)
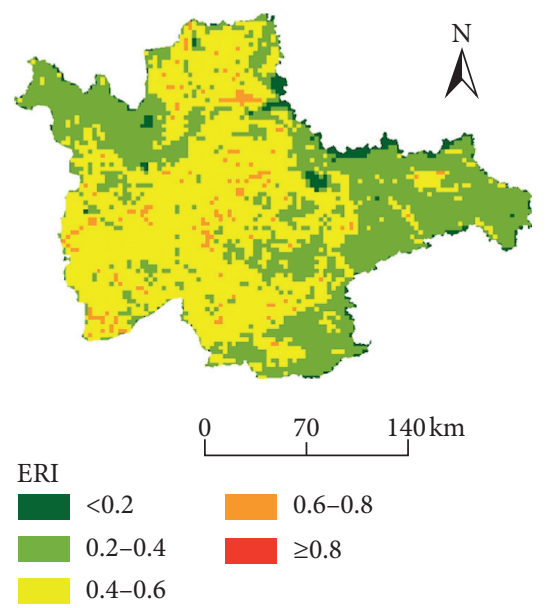

(d)
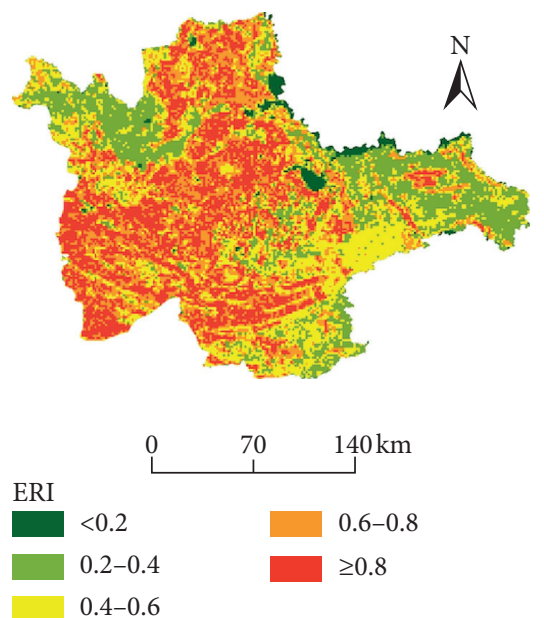

(g)

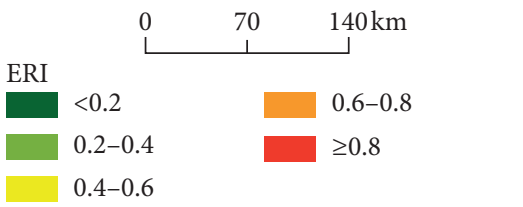

(b)
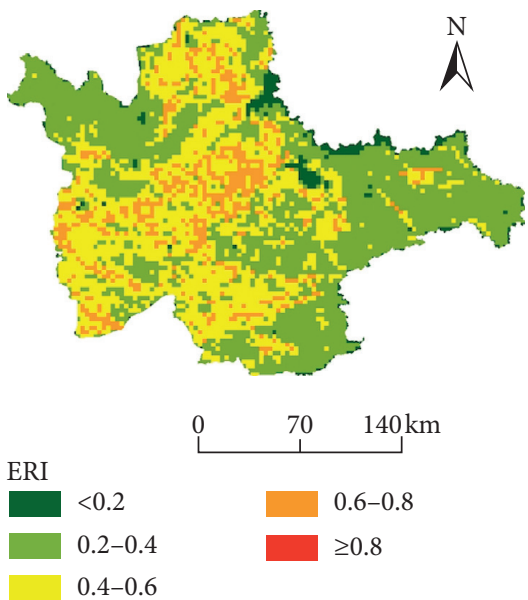

(e)
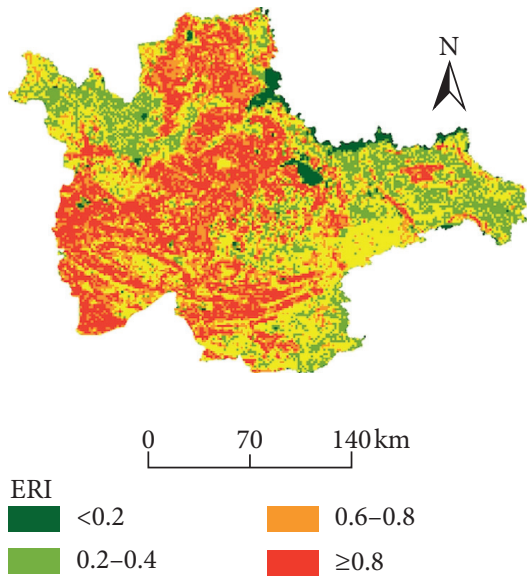

(h)

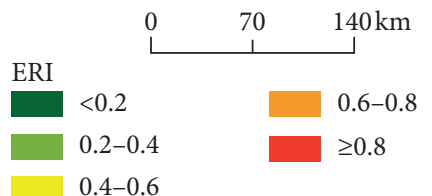

(c)
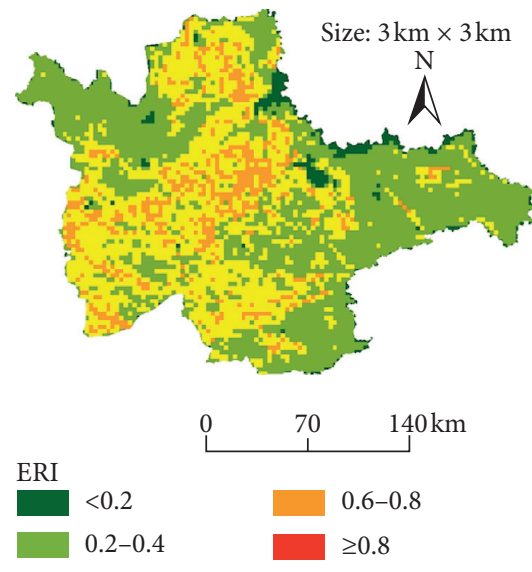

(f)
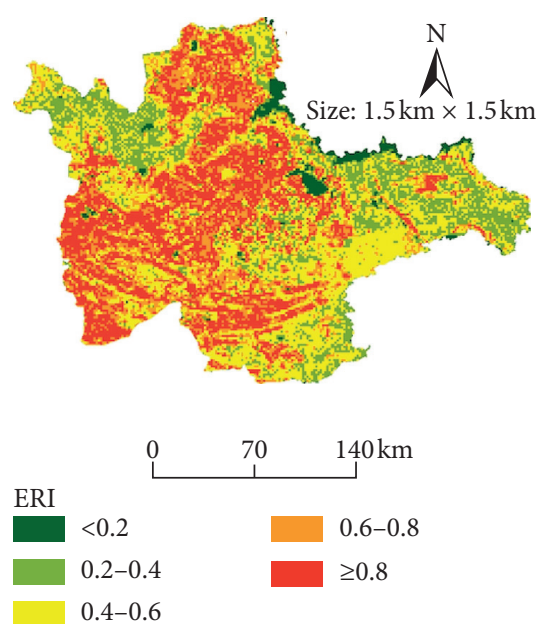

(i)

FIGURE 3: Ecological risk index at different spatial scales during the time intervals: (a) 1995a; (b) 2005a; (c) 2015a; (d) 1995a; (e) 2005a; (f) 2015a; (g) 1995a; (h) 2005a; (i) 2015a.

statistic-of ecological risk changes in different periods for the study region. These results appear in Figure 6. Evidently the hotspots in terms of the land-use ecological risk index in
Western Jilin Province from 1995 to 2015 were mainly distributed in its northern, central, and southwest urban core portions. The distribution characteristics of these 
TABLE 1: Moran's I of different research spatial scales during the time intervals.

\begin{tabular}{|c|c|c|c|c|c|}
\hline \multirow{2}{*}{ Size } & \multicolumn{3}{|c|}{ Moran's I } & \multirow{2}{*}{$P$ value } & \multirow{2}{*}{$Z$ score } \\
\hline & 1995 & 2005 & 2015 & & \\
\hline $5 \mathrm{~km} \times 5 \mathrm{~km}$ & 0.6044 & 0.6200 & 0.6209 & $<0.01$ & $>2.58$ \\
\hline $3 \mathrm{~km} \times 3 \mathrm{~km}$ & 0.7752 & 0.7339 & 0.7354 & $<0.01$ & $>2.58$ \\
\hline $1.5 \mathrm{~km} \times 1.5 \mathrm{~km}$ & 0.7618 & 0.7072 & 0.7080 & $<0.01$ & $>2.58$ \\
\hline
\end{tabular}

TABLE 2: Ecological risk index of land-use categories during the time intervals.

\begin{tabular}{lccccccccc}
\hline \multirow{2}{*}{ Categories } & \multicolumn{3}{c}{ Patch number } & \multicolumn{3}{c}{ Area $\left(\mathrm{km}^{2}\right)$} & \multicolumn{2}{c}{ ERI } & \multicolumn{2}{c}{. } \\
& 1995 & 2005 & 2015 & 1995 & 2005 & 2015 & 1995 & 2005 \\
\hline Cultivated land & 5087 & 5109 & 5128 & 24650.76 & 25052.42 & 25279.69 & 0.7335 & 0.7456 & 0.7525 \\
Forest land & 2659 & 2654 & 2683 & 2444.651 & 2440.702 & 2435.234 & 1.5188 & 1.5168 & 1.5183 \\
Grassland & 3146 & 3100 & 3120 & 5684.422 & 5104.998 & 5097.292 & 1.3415 & 1.2219 & 1.2218 \\
Water & 1772 & 1757 & 1762 & 2660.986 & 2495.632 & 2521.706 & 0.2784 & 0.2636 & 0.2661 \\
Construction land & 3764 & 3791 & 3805 & 1514.807 & 1540.05 & 1627.047 & 0.3922 & 0.3973 & 0.4115 \\
Unutilized land & 3668 & 3673 & 3663 & 9913.134 & 10235.01 & 9907.868 & 1.7848 & 1.8380 & 1.7851 \\
\hline
\end{tabular}

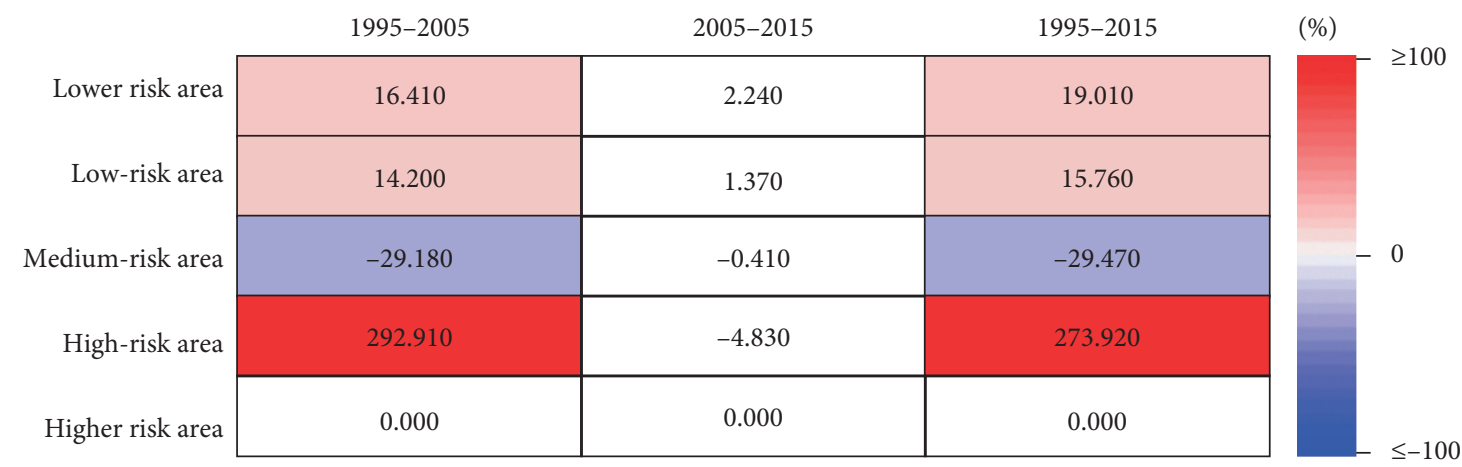

FiguRE 4: Change in coverage of five grades of ecological risk areas.

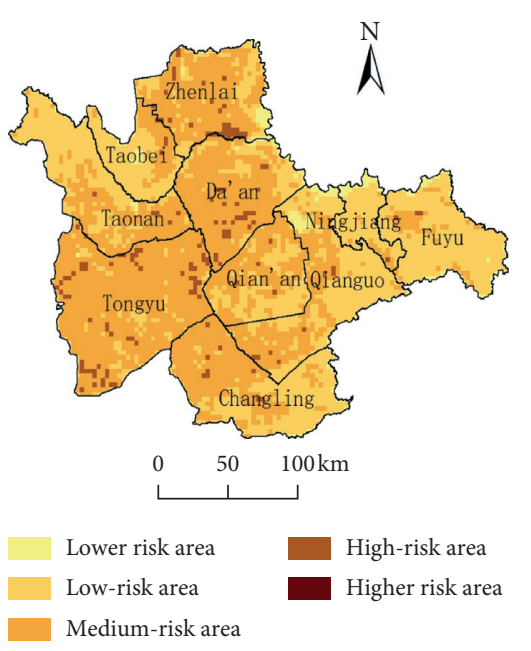

(a)

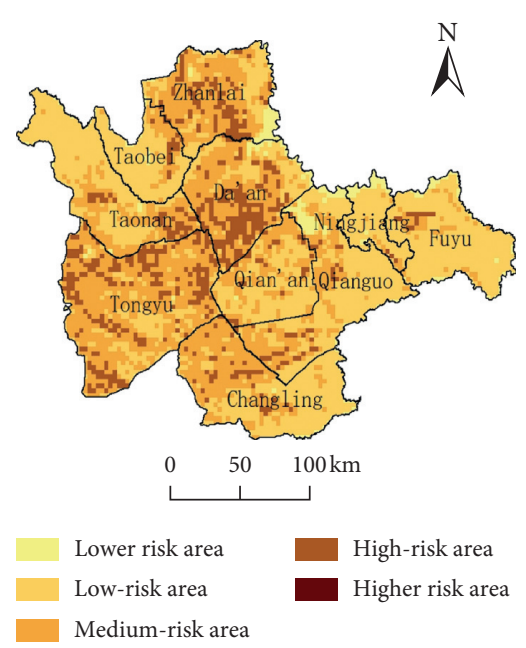

(b)

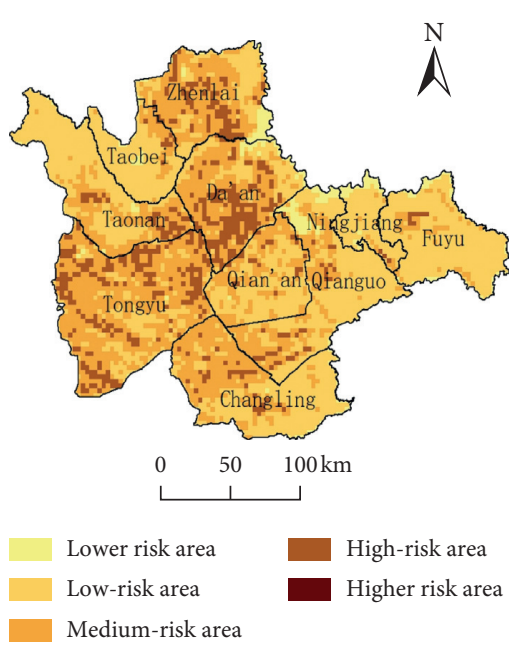

(c)

FIGURE 5: Spatial distributions of the ecological risk areas: (a) 1995a; (b) 2005a; (c) 2015a. 


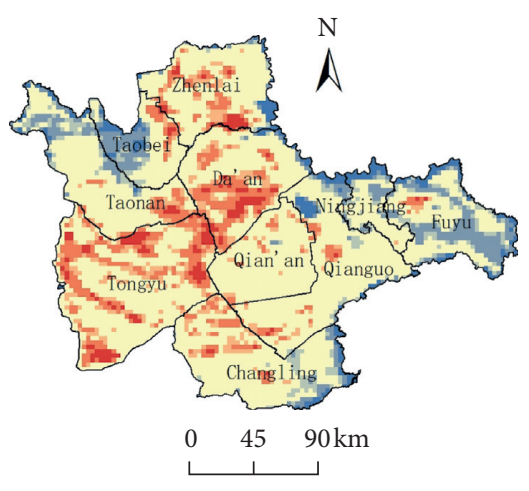

Cold spot-99\% confidence

Cold spot-95\% confidence

Cold spot-90\% confidence

High risk area

Hot spot-90\% confidence

Hot spot-95\% confidence

Hot spot-99\% confidence

(a)

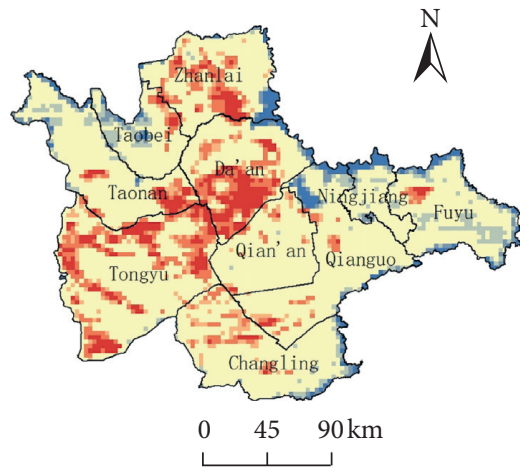

Cold spot-99\% confidence

Cold spot-95\% confidence

Cold spot-90\% confidence

High risk area

Hot spot-90\% confidence

Hot spot-95\% confidence

Hot spot-99\% confidence

(b)

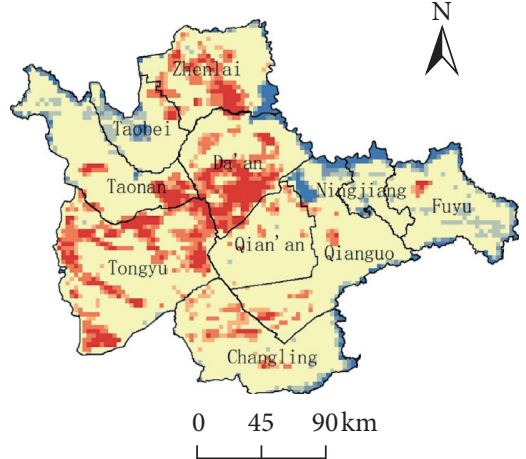

Cold spot-99\% confidence

Cold spot-95\% confidence

Cold spot-90\% confidence

High risk area

Hot spot-90\% confidence

Hot spot-95\% confidence

Hot spot-99\% confidence

(c)

FIgURE 6: The hotspot (and coldspot) analysis of the ecological risk index: (a) 1995a; (b) 2005a; (c) 2015a.

ecological risk hotspots indicated that the scope and timing of urban ecological land conversion to construction land have been enhanced considerably with more urbanization. Thus, the original landscape balance structure was disrupted, the ecological risk index of the urban core area was rapidly increased, the ecosystem became more fragile, and the ecological risk increased.

3.3. Land-Use Change Dynamic Characteristics. In 2015, the different land categories in Western Jilin Province were cultivated land at $25279.69 \mathrm{~km}^{2}$, unutilized land at $9970.87 \mathrm{~km}^{2}$, grassland at $5097.29 \mathrm{~km}^{2}$, water area at $2521.71 \mathrm{~km}^{2}$, forest land at $2435.23 \mathrm{~km}^{2}$, and construction land at $1627.05 \mathrm{~km}^{2}$. From Figure 7, we see that, from the perspective of change, the land coverage of grassland and water decreased significantly from 1995 to 2015, with annual land-use change intensity of $-0.516 \%$ and $-0.262 \%$, while that of both construction land and cultivated land significantly increased, by $7.41 \%$ and $2.56 \%$, respectively. Between 1995 and 2000, among the land categories, grassland and water underwent the greatest reduction in coverage, whereas since 2005 construction land has expanded, its land-use change rate and the corresponding land-use change intensity were the largest of all land categories assessed here. The proportion of cultivated land increased slightly over time, reaching $53.94 \%$ by 2015 . The area of forest land and unutilized land has remained relatively stable, with their proportional coverage only slightly changed.

3.4. Association Analysis between Ecological Risk and LandUse Change at the Patch Scale. To better explain the relationship between ecological risk and land-use change, we carried out a microanalysis of its dynamics at the patch scale of $3 \mathrm{~km} \times 3 \mathrm{~km}$. For this, 5517 risk units of the study region were separated to calculate indicators of a "changed ecological risk index value," "cultivated land change area," "forest land change area," "grassland change area," "water change area," "construction land change area," and "unutilized land change area," corresponding to the longest time interval (1995 to 2015), from which quadrant scatterplots were drawn (Figure 8).

Figure 8 indicates the changes of land-use types at the patch scale and their corresponding ecological risk values. The relationship between cultivated land and ecological risk was mainly distributed in the second quadrant, in which 345 points were significantly distributed; this indicated the ecological risk index declined as cultivated land expanded during the 1995-2015 period; the fluctuation in forest land coverage in the past 20 years is small, and while its relationship to ecological risk is not entirely self-evident, it seems less forest land will lead to more ecological risk. The relationship between grassland and ecological risk is mainly distributed in the third quadrant $(n=235)$, suggesting a reduction of grassland will worsen ecological risk; similarly, the reduction of water area will likely also exacerbate ecological risk. The extent of construction land had grown over the recent 20 years, such that increased individual patch units of construction land will probably reduce the ecological risk index (second quadrant, $n=41$ ), while most of the construction land use will increase. The relationship for changes between unutilized land and ecological risk was mainly concentrated in the first and third quadrants, indicating a greater unutilized land area will aggravate the ecological risk; conversely, reducing its area was expected to ameliorate ecological risk. 


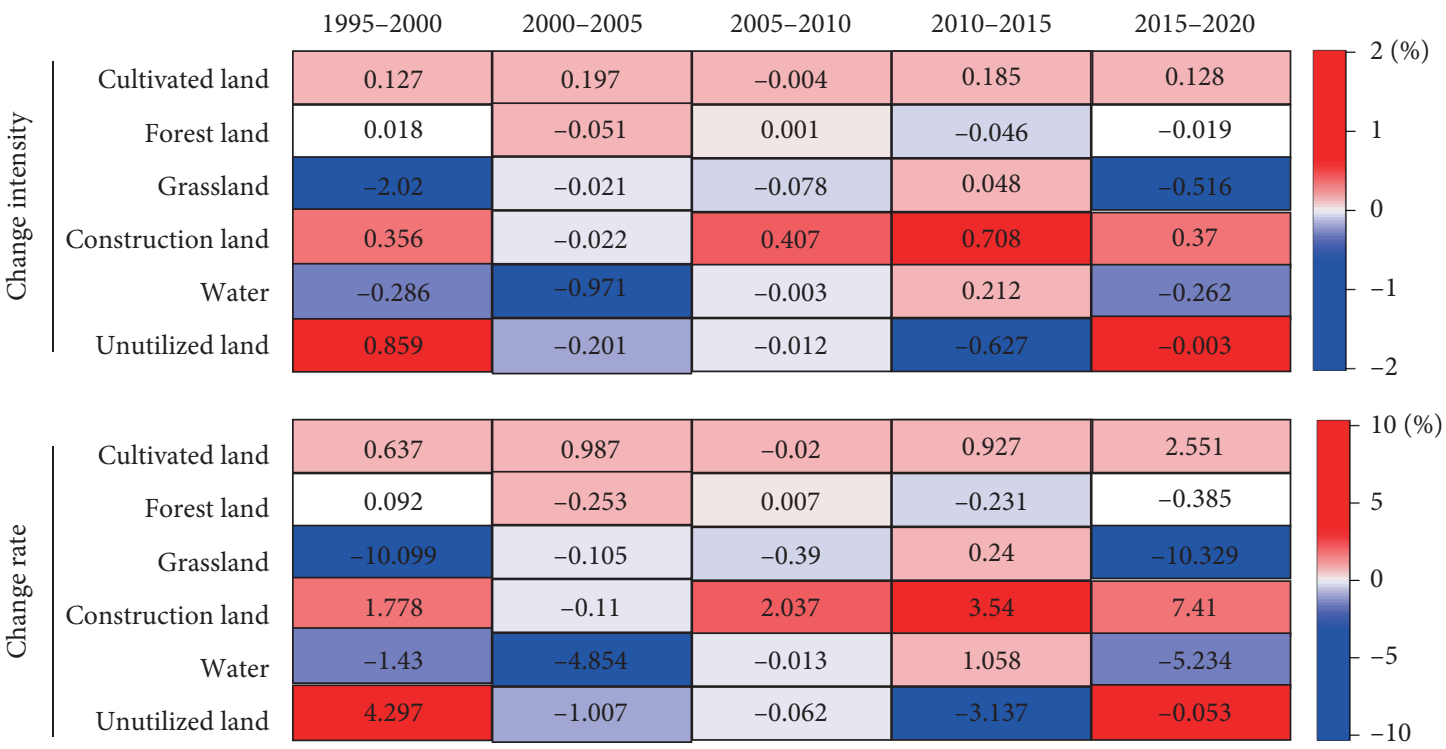

Figure 7: The change rate and change intensity during the three time intervals.
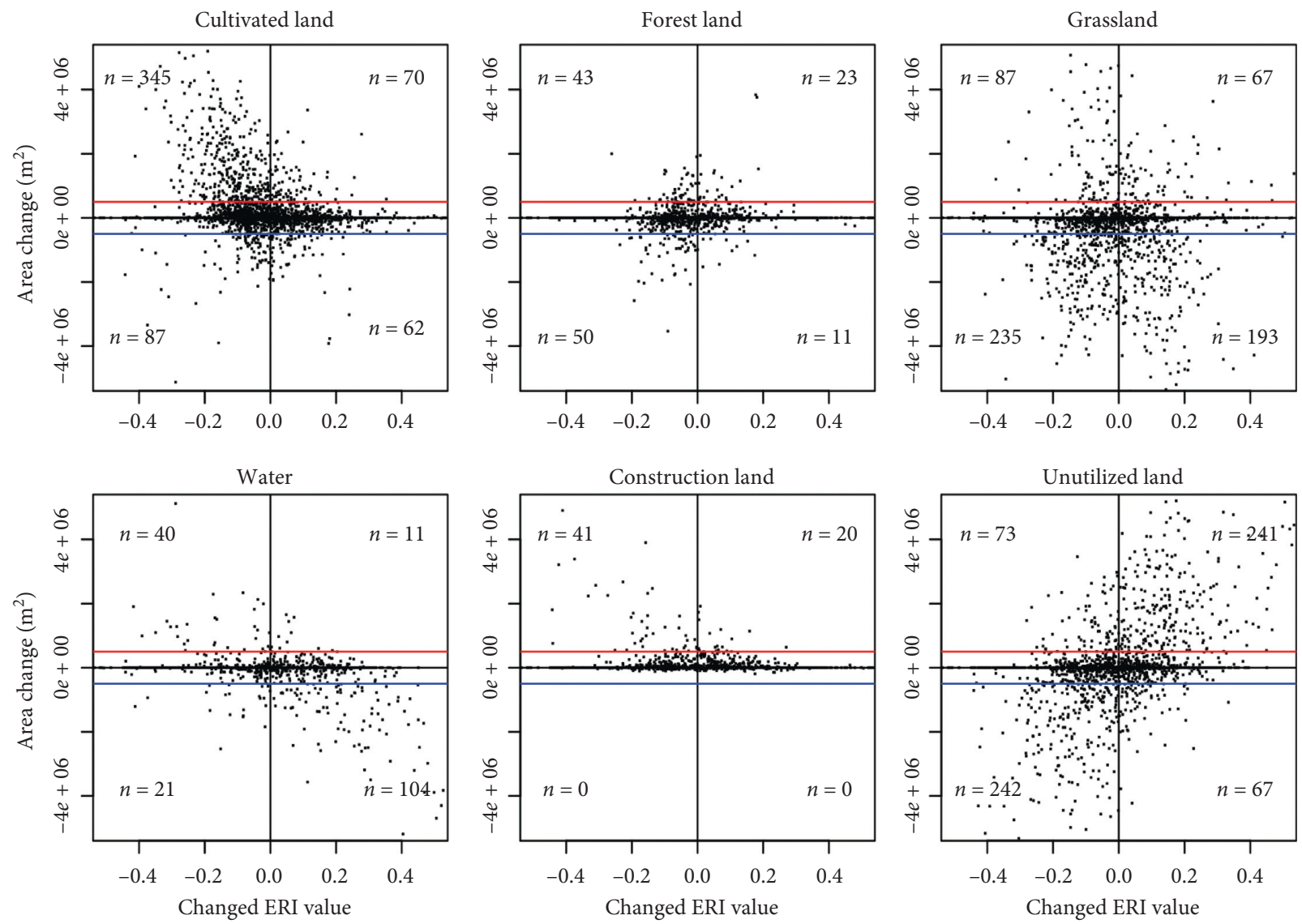

FIGURE 8: Scatterplots between the values of land-use change and ecological risk at the patch scale.

\subsection{Trajectories of Land-Use Change}

3.5.1. Land-Use Trajectories Changes. In 1995-2005 and 2005-2015, there were 36 land-use trajectory codes in Western Jilin Province, 30 of which were changed. To describe the transition type more intuitively, we show the area change rate of each track code in different colors, in matrix form (Figure 9), summarizing the main transition type (i.e., area change rate $\geq 0.08$ ), the secondary transition type $(0.08>$ area change rate $\geq 0.02)$, and the minimum 


\begin{tabular}{|c|c|c|c|c|c|c|}
\hline & \multicolumn{6}{|c|}{2005} \\
\hline & 1 & 2 & 3 & 4 & 5 & 6 \\
\hline 1 & 11 & 12 & 13 & 14 & 15 & 16 \\
\hline 2 & 21 & 22 & 23 & 24 & 25 & 26 \\
\hline & 31 & 32 & 33 & 34 & 35 & 36 \\
\hline 4 & 41 & 42 & 43 & 44 & 45 & 46 \\
\hline 5 & 51 & 52 & 53 & 54 & 55 & 56 \\
\hline 6 & 61 & 62 & 63 & 64 & 65 & 66 \\
\hline
\end{tabular}

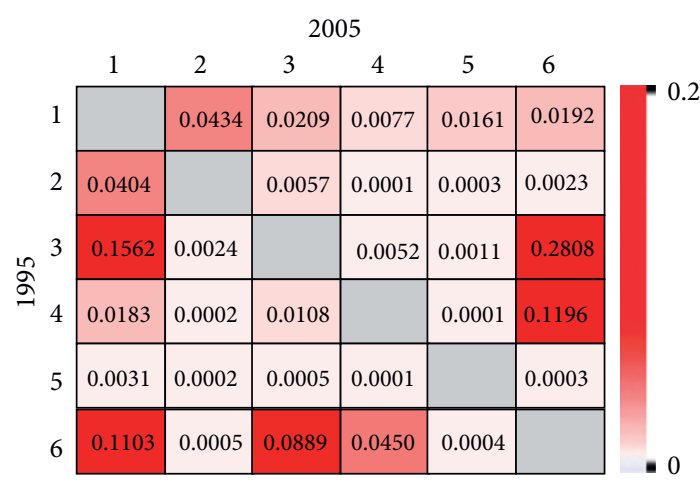

\begin{tabular}{|c|c|c|c|c|c|c|}
\hline & \multicolumn{6}{|c|}{2015} \\
\hline & 1 & 2 & 3 & 4 & 5 & 6 \\
\hline 1 & 11 & 12 & 13 & 14 & 15 & 16 \\
\hline 2 & 21 & 22 & 23 & 24 & 25 & 26 \\
\hline & 31 & 32 & 33 & 34 & 35 & 36 \\
\hline & 41 & 42 & 43 & 44 & 45 & 46 \\
\hline 5 & 51 & 52 & 53 & 54 & 55 & 56 \\
\hline 6 & 61 & 62 & 63 & 64 & 65 & 66 \\
\hline
\end{tabular}

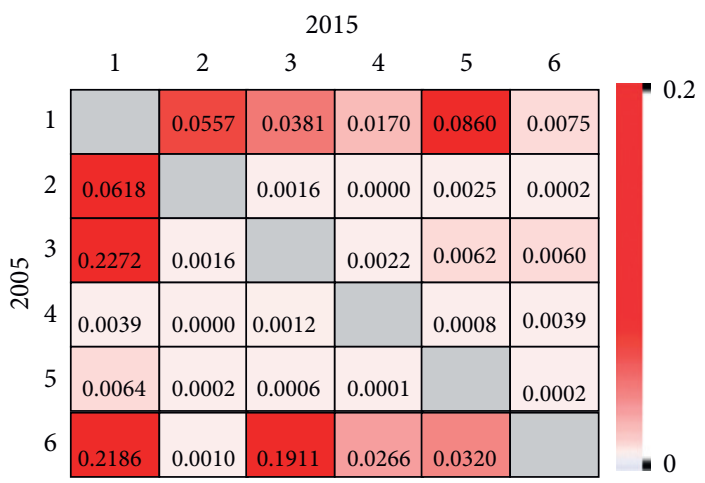

FIgURE 9: Heatmap plots for trajectories of land-over (upper panel) and the ratios of their corresponding area (bottom panel).

transition type $(0.02>$ area change rate). These results revealed that, going from 1995 to 2005, the net total area of land change in Western Jilin Province was $1816.699 \mathrm{~km}^{2}$, accounting for $3.88 \%$ of the study region's territory. The main transition types accounted for $75.59 \%$ of the changed land, having five track codes. The conversion of land-use types happened mainly between cultivated land, grassland, and unutilized land. Among the 30 trajectory codes, the secondary transition type had four track codes, accounting for $14.97 \%$ of the changed land, whereas the minimum transition type had 21 track codes, corresponding to just $9.44 \%$ of the changed land coverage. From 2005 to 2015, the changed land area was $724.6284 \mathrm{~km}^{2}$, accounting for only $1.55 \%$ of the study region's territory. The main transition types accounted for $72.28 \%$ of this changed land, for which four track codes dominated. The second transition type accounted for $26.97 \%$ of the changed land, and this has 14 track codes. The minimum conversion type accounted for $0.75 \%$ of the changed land, with 12 track codes.

3.5.2. Land Succession Type. Overall, 142 transition track codes of land-use change were found from 1995 to 2015. These results appear in Table 3 and Figure 9. According to the factors influencing the land type transformation, the latter can be divided into three types: unchanged land, human interference, and natural succession. The "unchanged type" refers to the kind of land that has not been altered spatially during the study period (e.g., "111," "222," and " 333 "). The "human interference type" refers to the land change caused by external factors (such as " 215 ," " 315 ," and "155") caused by the expansion of built-up area and land
TABLE 3: Land succession types during 1995-2015.

\begin{tabular}{lccc}
\hline Types & Areas $\left(\mathrm{km}^{2}\right)$ & Counts & $\%$ \\
\hline Human interference & 1342.59 & 110 & 2.86 \\
Natural succession & 1139.72 & 26 & 2.44 \\
Unchanged & 44386.44 & 6 & 94.70 \\
Total & 46868.75 & 142 & 100.00 \\
\hline
\end{tabular}

Note. The track codes of unchanged type are as follows: 111, 222, 333, 444, 555,666 ; those of natural succession type include $166,266,366,466,566$, $226,336,446,343,344,334,346,433,444,463,464,633,634,636,643,644$, 643,664 ; the rest are human interference types.

reclamation, indicative of the influence of human activities upon land-use change dynamics. "Natural succession" refers to natural land changes that proceed with little impact from human activities (e.g., codes "366" and "344").

From 1995 to 2015, the unchanged land area accounted for $94.7 \%$ of the total area of the study region, consisting mainly of cultivated land. To some extent, the land-use patterning in Western Jilin Province has remained relatively stable over the 20 recent years. The changed area of the human interference type amounted to $1342.59 \mathrm{~km}^{2}$, with 110 track codes for it; this accounts for $2.86 \%$ of the study's region territory. Further, human disturbance frequently changed the land type, yet the intensity of this interference is not large. The changed area of the natural succession type was $1139.72 \mathrm{~km}^{2}$ or $2.44 \%$ of the study region. For it, 26 track codes in total were discernable, which suggested the landscape's natural succession changed little over time.

As Figure 10 shows, land-use change caused by human interference was mainly distributed in Zhenlai and Taobei in the north, Qian'guo and Ningjiang in the east, and 


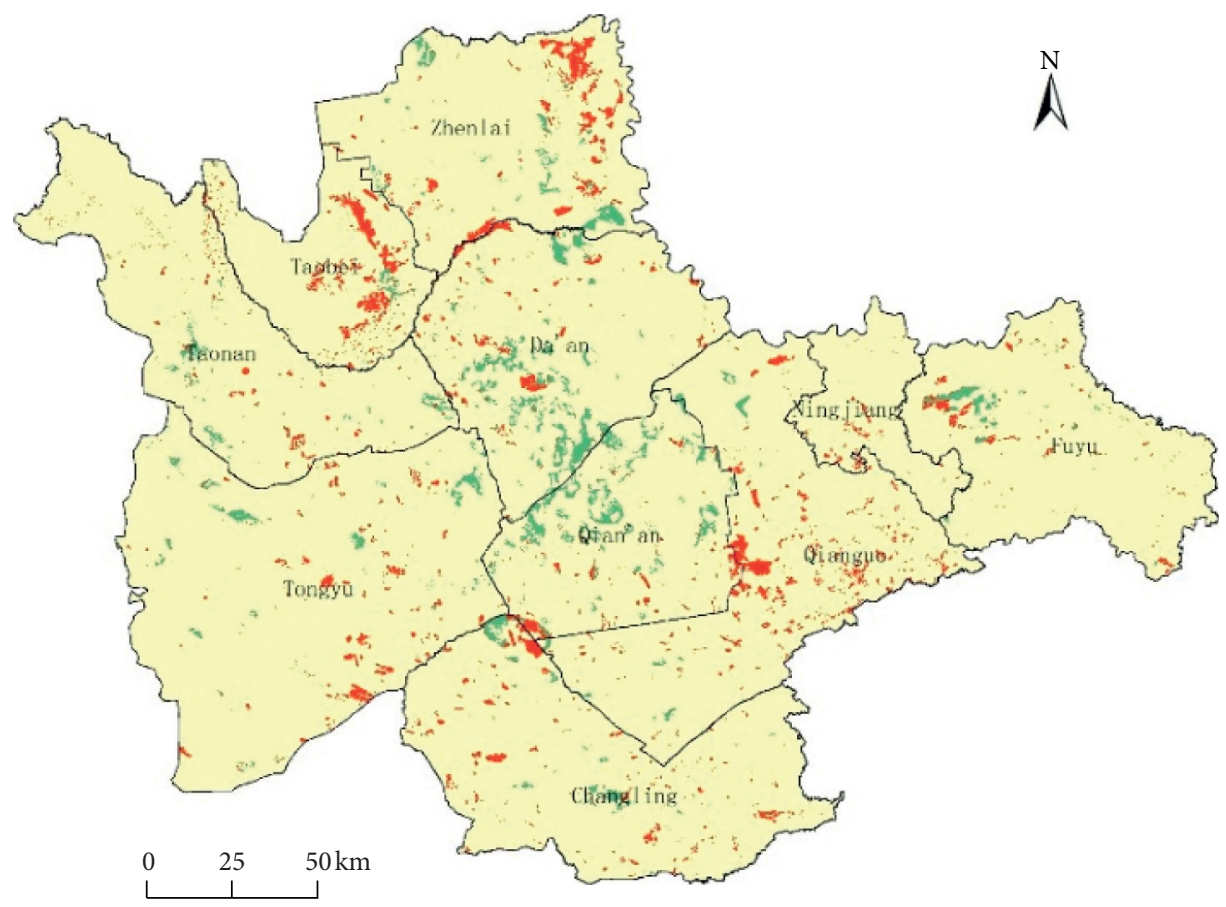

Human interference

Natural succession

Unchange

FIGURE 10: Land succession types in the 1995-2015 period.

sporadically distributed in Changling and Tongyu. The natural succession changes were mainly distributed in Chagan Lake Reserve in the middle of the study region, surrounded by platforms, with the low-lying terrain whose drainage is poor. Accordingly, soil salinization and land degradation have gradually intensified there in recent years.

\section{Discussion}

Firstly, the landscape categories in Western Jilin Province, our study region, are mainly cultivated land and grassland, and its overall landscape distribution is relatively stable. However, as urbanization advanced, complex intersections between different landscape types emerged in different periods. As urbanization continues to expand, grassland rapidly declines, and the wetland areas continue to shrink, leaving the land-use structure in an unsustainable state, which gradually leads to many environmental problems, such as soil salinization and erosion. Moreover, the largescale degradation of grasslands has disrupted continuous ecological land-use patterns. Thus, the ecological vulnerability and risk of the earth surface were both further elevated. However, since unsustainable land use and human activities make the management of degraded lands more difficult, the degree of risk posed to the ecological environment in study region is still rapidly increasing.

Secondly, the land-use change trajectory analysis shows that forms of human interference, mostly cultivated land reclamation and urban sprawl, have become the main factors driving ecological risk change. Additionally, with agricultural technology improvement and the benefits of planting of cash crops, farmers will actively convert some available ecological land to cultivated land. Conversely, however, these scattered individual behaviors can only reclaim limited and scattered patches of cultivated land, breaking the centralized pattern of ecological land use and causing severe fragmentation of the land, which intensifies the degree of ecological risk. Driven by recent years' social development and technological advances, the expansion of industrial land plays an ever-stronger role in destroying the continuity of ecological land-use resilience and patterning.

Thirdly, the ultimate purpose of landscape ecological risk assessment is to provide a scientific theoretical basis for regional-scale decision-making in the management of the ecological environment. To maintain regional land security and protect the structure and function of regional ecosystems, differing risk management measures should be tailored and taken for different types of ecological risk areas, so as to promote the sustainable use of regional land resources. This high-risk area is mainly concentrated in the central and western regions of the study region. In Zhenlai, Da'an, and Tongyu, the terrain is low lying, and the soil quality is poor, so it is faced with severe risks of land salinization and desertification. In view of the need to adhere to the windbreak and sand fixation projects there, we should aim to maintain the achievements of returning farmland to forest and grassland and to also conserve water resources. At the same time, there are many wetlands in this area, and their fragility 
on the landscape is high. Especially under the influence of human activities, the degree of fragmentation of this wetland landscape is intensifying. It is therefore necessary to strengthen the protection of wetland resources and maintain the ecological diversity.

The medium-risk area is mainly concentrated in the Middle East and north of the study region, where one finds much grassland and cultivated land, but the integrity of these patches is not strong. The main risk sources were excessive reclamation and grazing. In view of this situation, it is necessary to formulate a reasonable grazing policy and strengthen the protection of grassland resources, especially natural native grassland vegetation. The low ecological risk areas are concentrated in Fuyu, Ningjiang, Taobei, and Taonan areas. Compared with the high ecological risk ones, these areas have terrain on higher ground and a better soil texture, which are suitable for crop cultivation. Nevertheless, it is still necessary to control reclamation and protect regional ecological diversity there.

Due to the limitations of researchers' experience and knowledge levels, the determination of a landscape fragility index $\left(F_{i}\right)$ can be adopted to reflect the relative vulnerability of land-use types. Moreover, a better expression method is needed to be improved. We should also strengthen the ecological interpretation of the landscape index and ideally establish a robust landscape ecological risk assessment model based on quantified ecological processes and mechanisms. Additionally, in later research, we could aim to optimize the spatial allocation of regional land-use types from the perspective of ecological risk zoning.

\section{Conclusions}

During 20 years in our study, the ecological risk to land in the western part of Jilin Province has been increasing in space because of serious human interference and severe land degradation. The transformation of land-use types has frequently occurred, mainly as reduced grassland coverage and water at the expense of more construction land. Human social activities play dominating roles in driving the land-use patterns found here. Under the joint action of changes to natural conditions and ongoing human social activities, soil salinization has caused severe grassland degradation and wetland reduction in the study region. In the late 1990s, the improved land policy contributed immensely to the protection of ecological land, such that the worsening ecological risk has been partly mitigated and the ecological landscape pattern has undergone improvement. Land-use dynamic change describes the relationship between land-use changes and transformations. Finally, it is of great significance to study the regional ecological security of the lands' ecosystems by analyzing the factors influencing both the landscape and changes in ecological risk.

\section{Data Availability}

The data used to support the findings of this study are included within the article.

\section{Conflicts of Interest}

The authors declare that they have no conflicts of interest.

\section{Acknowledgments}

The authors would like to thank Dr. Dong Liguo for providing suggestions and revising manuscript. The authors also thank the key project of National Natural Science Foundation of China "Research on spatial process and comprehensive effect of Northeast Revitalization" (no. 41630749).

\section{References}

[1] E. F. Lambin and P. Meyfroidt, "Global land use change, economic globalization, and the looming land scarcity," Proceedings of the National Academy of Sciences, vol. 108, no. 9, pp. 3465-3472, 2011.

[2] Y. Liu, S. Lu, and Y. Chen, "Spatio-temporal change of urbanrural equalized development patterns in China and its driving factors," Journal of Rural Studies, vol. 32, pp. 320-330, 2013.

[3] J. A. Foley, R. DeFries, G. P. Asner et al., "Global consequences of land use," Science, vol. 309, no. 5734, pp. 570-574, 2005.

[4] H. Xie, Y. He, and X. Xie, "Exploring the factors influencing ecological land change for China's Beijing-Tianjin-Hebei Region using big data," Journal of Cleaner Production, vol. 142, 2016.

[5] W. G. Landis and J. K. Wiegers, "Ten years of the relative risk model and regional scale ecological risk assessment," Human and Ecological Risk Assessment: An International Journal, vol. 13, no. 1, pp. 25-38, 2007.

[6] S. Hongbo, Y. Guishan, S. Weizhong, and W. Rongrong, "Research progress of ecological risk assessment," Journal of Ecology, vol. 28, pp. 335-341, 2009.

[7] V. M. B. Moraes, R. D. Malheiros, V. Bruggeman et al., "The effect of timing of thermal conditioning during incubation on embryo physiological parameters and its relationship to thermotolerance in adult broiler chickens," Journal of Thermal Biology, vol. 29, no. 1, pp. 55-61, 2004.

[8] L. Yuefen, Study on Grassland Ecological Environment Evaluation and Expert System in Western Jilin Province, Jilin University, Changchun, China, 2004.

[9] Z. Fengqin, Study on Land Ecological Environment Security in Western Jilin Province, Jilin University, Changchun, China, 2005.

[10] S. Gold, W. Zhengfang, and D. Haibo, "Characteristics of climate change in semiarid area of western Jilin province in recent 50 years," Resources and Environment in Arid Area, vol. 28, pp. 190-196, 2014.

[11] B. Shuting, "Study on landscape ecological risk assessment of western Jilin based on land use change," Master thesis, Jilin University, Changchun, China, 2019.

[12] F. Zaiyi and X. Xuegong, "Risk assessment of regional ecology," Progress in Earth Science, vol. 2, pp. 267-271, 2001.

[13] C. Hui, L. Jinsong, C. Yu, L. Shuangcheng, and O. Hua, "Research progress of ecological risk assessment," Journal of Ecology, vol. 28, no. 2, pp. 335-341, 2006.

[14] Z. Shuying, L. Xin, and Z. sichong, "Ecological risk analysis of land use in Daqing city based on GIS," Journal of Natural Disasters, vol. 14, no. 4, pp. 141-145, 2005. 
[15] S. Zhicai, Y. Xiaolu, and Z. Jingqiu, "Vulnerability and spatial association pattern of landscape pattern in lower Liaohe plain," Journal of Ecology, vol. 34, pp. 247-257, 2014.

[16] Y. Jun, G. lucidum, X. Jianchao, L. Xueming, and G. Quansheng, "Land use pattern evolution and ecological effects of Nansihu wetland," Resource Science, vol. 36, pp. 856-864, 2014.

[17] B. Mertens and E. F. Lambin, "Land-cover-change trajectories in southern Cameroon," Annals of the Association of American Geographers, vol. 90, no. 3, pp. 467-494, 2000.

[18] Q. Zhou, B. Li, and A. Kurban, "Trajectory analysis of land cover change in arid environment of China," International Journal of Remote Sensing, vol. 29, no. 4, pp. 1093-1107, 2008.

[19] W. Ruiqiang, Landscape Pattern Change and Ecological Risk Assessment of Coastal Zone, Hainan Normal University, Haikou, China, 2011. 